\title{
The Small Incision Fenestration for Lumbar Disc Herniation Complicated with Lumbar Spinal Stenosis
}

\author{
G. ZHU, L. CHENG* AND X. CAI \\ Department of Orthopedics, Suzhou Municipal Hospital, Suzhou, 215000, China
}

Zhu et al.: The Small Incision Fenestration for Lumbar Disc Herniation

\begin{abstract}
The paper aims to assess clinical effect of small incision fenestration for lumbar disc herniation complicated with lumbar spinal stenosis and provide more adequate scientific guiding basis for clinical treatment. In this paper, clinical data of $\mathbf{1 2 0 0}$ lumbar disc herniation patients with lumbar spinal stenosis who were hospitalized during June 2014 and June 2015 were retrospectively analyzed. Depending on their different treatment options, the patients were divided into two groups: 550 cases of control group patients underwent conventional surgery, 650 cases of observation group patients received small incision fenestration. The two groups of patient's operation time, intraoperative blood loss and postoperative hospital stay were recorded in detail. Clinical results of the two groups of surgical treatment were evaluated and compared with visual analog scale pain grade score and lower back pain Japanese orthopaedic association scoring system. The treatment results showed that operation time, postoperative hospital stay and intraoperative blood loss of observation group were significantly less than those of control group. Comparison between groups, $\mathbf{p}<0.05$, statistically significant; visual analog scale score and Japanese orthopaedic association score result showed significant superiority of observation group therapy compared to control group. Statistical difference of $\mathbf{p}<\mathbf{0 . 0 5}$ is statistically significant. It can thus be known that small incision fenestration enjoys significant clinical effect for lumbar disc herniation complicated with lumbar spinal stenosis is with important clinical promotion value.
\end{abstract}

Key words: Lumbar spinal stenosis, lumbar disc herniation, small incision fenestration, clinical effect

Lumbar disc is located between various centrum of vertebra as an integral part of joints of lumbar vertebra, which supports, connects and buffers lumbar vertebra. Shaped like a squashed abacus beads, it consists of three parts of nucleus pulposus, cartilage plat, fiber ring $^{[1]}$. When fiber ring kyphosis or rupture, nucleus pulposus prolapse are caused due to trauma, degeneration, etc. it is called lumbar disc herniation. Because spinal cord passes from posterior of the disc, when protruding disc compresses spinal nerve or cauda equina and leads to back leg pain or incontinence and even causes paralysis, it is called lumbar disc herniation (fig. 1 and fig. 2) ${ }^{[2]}$. Lumbar spinal stenosis refers to a corresponding nerve dysfunction disease caused by spinal cord path shortening, compression of dural sac, spinal cord or nerve roots due to a variety of reasons. It is one of the common causes of common lumbar diseases such as low back pain and back leg pain, also known as lumbar spinal stenosis syndrome. Under normal circumstances, there is no symptom when patients have a rest. But after a walk, there will be symptoms such as leg pain, numbness, weakness, which will be eased after one squats or sits down to have a rest before continued walking ${ }^{[3,4]}$. Lumbar disc herniation complicated with lumbar spinal stenosis is a common orthopedic clinical disease. A lot of experiences have shown that a main feature of the disease is intermittent claudication. In acute period, patients will have more obvious pain; in chronic period when patients are inactive, generally there will be no pain. Moreover, occurrence of the disease might also lead to other complications $^{[5-7]}$. Recent years shows increasing number of patients with the disease in orthopedic clinic, which makes how to further improve therapeutic effect of lumbar disc herniation complicated with lumbar spinal stenosis has become an important subject of clinical studies. Some empirical results of clinical treatment show that traction, massage, reset recovery methods for lumbar disc herniation complicated with lumbar spinal stenosis may aggravate intra spinal soft

*Address for correspondence

E-mail: szlcheng@163.com 
tissue irritation and nerve root edema, causing exacerbations ${ }^{[8-11]}$. Laminectomy method, although more common, may lead to spinal stenosis, scar adhesions and a host of other complications, resulting in greatly reduced therapeutic effect and even seriously affecting patients quality of life. In order to effectively alleviate these problems and improve clinical treatment efficiency of the disease, this paper carried out indepth inquiry into specific clinical effects of smaller incision fenestration as details shown below (fig. 3). The study objects were 1200 lumbar disc herniation patients complicated with lumbar spinal stenosis who were hospitalized between June 2014 and June 2015, to be divided into two groups according to different treatment options. There were 650 cases in observation group: 364 male cases, 286 female cases; the average age was $(56.4 \pm 6.2) \mathrm{y}$; average duration lasted $(7.53 \pm 2.42) \mathrm{y}$; there were 550 cases in control group: 298 male cases, 252 female cases; the average age was $(57.4 \pm 6.4)$ y; average duration lasted $(7.84 \pm 2.42) \mathrm{y}$; the two groups of patients were in line with clinical symptoms and image diagnostic criteria (fig. 4) of lumbar disc herniation complicated with lumbar spinal stenosis, who voluntarily chose appropriate surgical treatment and signed informed consent. Comparison of basic data of the two groups revealed no statistical significance ( $p>0.05$ ). Results of the two groups were comparable. Control group patients received posterior laminectomy and decompression with combined spinal epidural anesthesia first. Median incision on patients waist was performed, exposing lamina of lumbar vertebra, symptomatic vertebrae, facet and transverse process ${ }^{[12]}$. Then C-arm fluoroscopic unit was used for accurate positioning of symptomatic vertebrae, with pedicle screw embedded in centrum. T-drill was used for drilling, locating pin was imbedded and pedicle screw was twisted into the drilled hole. Hardened, thickened vertebral plate and ligamentum flavum were removed, protruding intervertebral disc was removed and nerve root was expanded. Screws and nuts were then tightened before bone graft. Observation group received small incision fenestration for treatment, with specific treatment measures as follows. Patient's maintained prone position, the belly was suspended with dedicated spinal surgery frame and continuous epidural anesthesia was done. Patient's preoperative computed tomography (CT) diagnosis was analyzed before positioning. Determine fenestration point and judge whether fenestration points were on the same side, in order to determine length and location of surgical incision. While determining fenestration point, to avoid or reduce damage to the bone, laminae interval space should be chosen for fenestration as far as possible. During surgery, narrow edged periosteal detacher was selected to separate ligamentum flavum adhered to the upper and lower edge of vertebral plate. During separation, it should be noted that periosteal detacher should cling to anteromedial surface of vertebral plate in separation, with one third portion of upper and lower vertebral plate removed, thereby forming a small window, which facilitated surgical procedure. Use tissue forceps to lift lower edge of ligamentum flavum, observe endorhachis and ligamentum flavum and use thin nerve stripper to separate it while moving it forward. Remove ligamentum flavum, find and protect the nerve root and then make targeted treatment of herniated disc and stenosis issues. Remove outer ligamentum flavum and about one third of anteromedial superior articular process with lamina forceps, separate dura mater and nerve roots, push venous plexus open, expand it so that herniated disc can be exposed. Then cut longitudinal ligament and fiber ring and remove nucleus pulposus. Successively cut bone at the trailing edge of centrum with bone knife for hyperplasia, bone protrusion, posterior longitudinal ligament calcification. In case of nerve root oppression, lower side lateral recess and nerve roots exit should be expanded so that it is loose. If patient has obvious cauda equina symptoms, spinous process base inner plate should be eliminated, with normal epidural fat retained. Coverage of fat sheet can be used to reduce epidural adhesions. For multi space disease patients, bilateral or multi segmental fixed point fenestration can be provided. After decompression, compress with saline soaked gauze for some time and rinse surgery wound with warm saline, then proceed with regular negative pressure drainage and complete wound closure. Operation time, intraoperative blood loss, postoperative hospital stay of the two groups of patients was compared. Pain of the two groups of patients after treatment was compared with visual analog scale (VAS) score (a lower score indicates lighter pain) and postoperative lumbar nerve function of the two groups of patients was compared with Japanese orthopaedic association (JOA) score (a higher score indicates good recovery of lumbar neurological function). The study adopted SPSS 21.0 statistical software for data analysis and processing. Count data were expressed by (n, \%), to be tested by chi square, measurement data were expressed by $(\overline{\mathrm{x}} \pm \mathrm{s})$, to be tested by t. Only when $\mathrm{p}<0.05$ is met, difference is deemed to be statistically significant. The treatment results showed that, operation time, 
intraoperative blood loss and hospital stay of observation group were significantly less than those of control group. Comparison between groups $\mathrm{p}<0.05$, statistically significant; VAS score and JOA score showed that, compared to control group, observation group therapy enjoys significant advantages. Statistical difference, $\mathrm{p}<0.05$ is statistically significant. Table 1 and Table 2 below show the detail data. This study aims to evaluate clinical effect of small incision fenestration for lumbar disc herniation complicated with lumbar spinal stenosis. In small incision fenestration, general anesthesia of patients is needed, whose primary purpose is to further shorten operation time, reduce patient's surgical pain. It is not difficult to find from the study results that, operation time and postoperative pain of observation group patients are significantly less than that of control group patients, comparison between groups $p<0.05$ is statistically significant. In addition, surgical wound of small incision fenestration is relatively small with less lumbar tissue peeling, so integrity of lumbar spine can be better protected, which reduces amount of bleeding during surgery, further shortens patients postoperative recovery and improves clinical efficiency. The study results revealed that intraoperative blood loss, postoperative hospital stay and recovery of lumbar nerve function of observation group patients were significantly better than those of control group patients, comparison between groups $\mathrm{p}<0.05$ is statistically significant. In summary, small incision fenestration enjoys such advantages as small surgical wound, fast recovery and good therapeutic effect in clinical treatment of lumbar disc herniation complicated with lumbar spinal stenosis, so the treatment method should be widely applied in clinic.

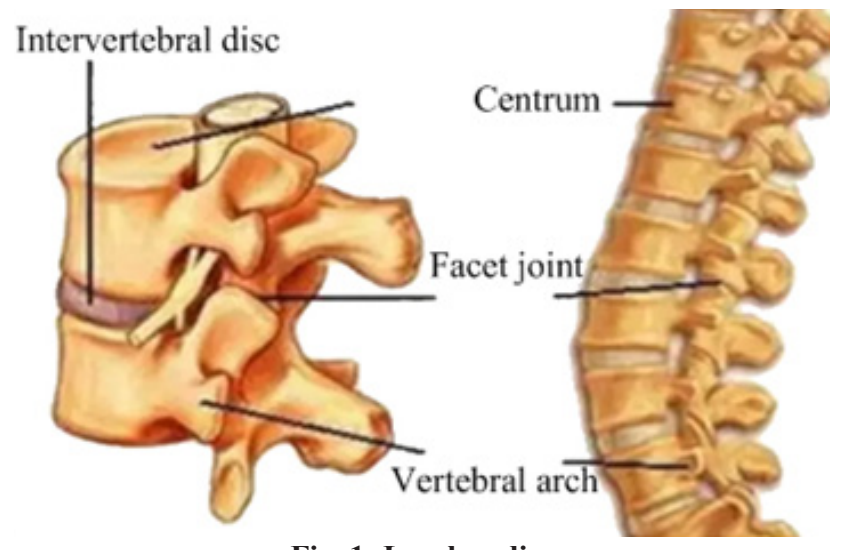

Fig. 1: Lumbar disc

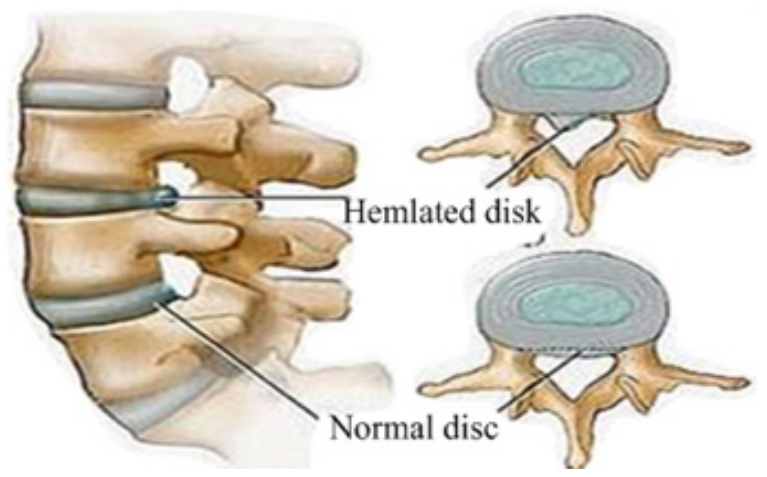

Fig. 2: Lumbar disc herniation

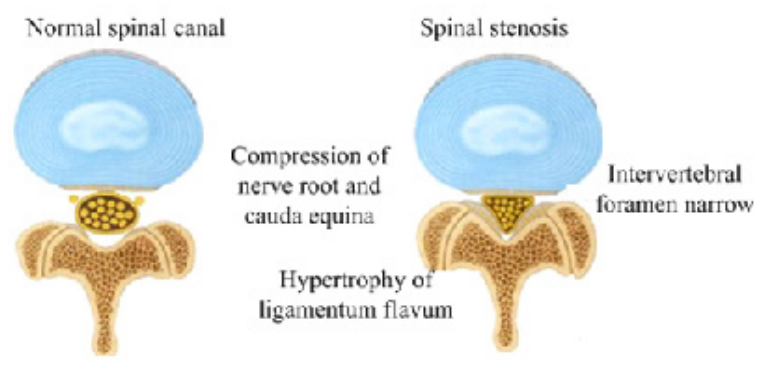

Fig. 3: Lumbar spinal stenosis

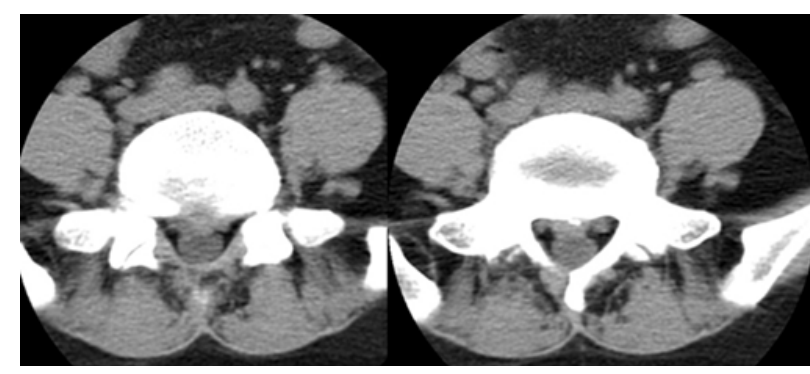

Fig. 4: CT image of lumbar disc herniation patients

TABLE 1: TREATMENT COMPARISON OF THE TWO GROUPS ( $\bar{x} \pm \mathbf{s})$

\begin{tabular}{lccc}
\hline Group & $\begin{array}{c}\text { Operation } \\
\text { time }(\mathrm{min})\end{array}$ & $\begin{array}{c}\text { Intraoperative } \\
\text { blood loss }(\mathrm{ml})\end{array}$ & $\begin{array}{c}\text { Hospital stay } \\
(\mathrm{d})\end{array}$ \\
\hline $\begin{array}{l}\text { Observation } \\
\text { group }(\mathrm{n}=650)\end{array}$ & $59.84 \pm 2.62$ & $49.56 \pm 2.74$ & $5.12 \pm 1.84$ \\
$\begin{array}{l}\text { Control group } \\
(\mathrm{n}=550)\end{array}$ & $91.55 \pm 3.87$ & $72.43 \pm 3.65$ & $7.52 \pm 2.32$ \\
$\mathrm{t}$ & 168.410 & 123.766 & 19.975 \\
$\mathrm{p}$ & 0.000 & 0.000 & 0.000 \\
\hline
\end{tabular}

TABLE 2: VAS, JOA SCORE RESULT, COMPARISON OF THE TWO GROUPS ( $\bar{x} \pm s$ )

\begin{tabular}{lccc}
\hline Group & VAS score & JOA score \\
\hline $\begin{array}{l}\text { Observation } \\
(\mathrm{n}=650)\end{array}$ & group & $2.12 \pm 1.15$ & $29.43 \pm 2.18$ \\
$\begin{array}{l}\text { Control } \\
(\mathrm{n}=550)\end{array}$ & group & $5.37 \pm 2.04$ & $21.23 \pm 1.76$ \\
$\mathrm{t}$ & 36.632 & 70.819 \\
$\mathrm{p}$ & 0.000 & 0.000 \\
\hline
\end{tabular}




\section{Conflicts of Interest:}

The authors declared no conflict of interest.

\section{REFERENCES}

1. Liu SY, Lin YM, Wei TS, Lin SJ, Liu CC, Chou CW. Exacerbation of symptoms of lumbar disc herniation complicated by a schwannoma: a case report. Kaohsiung J Med Sci 2007;23(9):480-5.

2. Huang JL, Yang YF, Liang SW. On small incision fenestration for lumbar disc herniation complicated with lumbar spinal stenosis. Hebei Med 2012;18(11):1626-8.

3. Ding XB, Wu SM. Effect of small incision fenestration for lumbar disc herniation complicated with lumbar spinal stenosis. Contemp Med Forum 2015;13(2):221-2.

4. Sonmez E, Yilmaz C, Caner H. Development of lumbar disc herniation following percutaneous vertebroplasty. Spine 2010;35(3):E93-5.

5. Mei XD, Yang B, Xiong XF. Clinical analysis of 45 cases of lumbar disc herniation complicated with lumbar spinal stenosis treated with small incision fenestration. Jilin Med J 2015;5:933.

6. Her Y, Kang SH, Cho YJ, Yang JS, Jeon JP, Choi HJ. Factors associated with longer postoperative outpatient followup duration in patients with single lumbar disc herniation: A noncomplicated patient cohort study. Neurospine 2018;15(3):225
7. Lin FH. Clinical efficacy study on small incision fenestration for lumbar disc herniation complicated with lumbar spinal stenosis. Med J Indian Enterpr 2015;28(5):1671-2.

8. Guan GY. Clinical study of small incision fenestration for lumbar disc herniation with lumbar spinal stenosis. Chin J Med Res 2013;11(20):6-7.

9. Zhang ZC, Zhang Y, Zhang LZ, Du P, Li F, Sun TS. Comparative study of Dynesys dynamic internal fixation and fusion through small incision intermuscular approach in the treatment of lumbar disc herniation. Chin J Bone Joint Inj 2020;9(10):762-6.

10. Liu Y, Li HB, Qian W. Clinical analysis of small incision fenestration discectomy in the treatment of lumbar disc herniation. Med Innov China 2015;12(5):48-50.

11. Sun YX, Yin W, Yu J. Effect of small incision fenestration for lumbar disc herniation complicated with lumbar spinal stenosis. Chin Health Stand Manag 2016;28(1):59-61.

12. Cui HT. Clinical analysis of small incision fenestration in the treatment of lumbar spinal stenosis combined with lumbar disc herniation. Chin Health Stand Manag 2015:6(13):44-5.

This is an open access article distributed under the terms of the Creative Commons Attribution-NonCommercial-ShareAlike 3.0 License, which allows others to remix, tweak, and build upon the work non-commercially, as long as the author is credited and the new creations are licensed under the identical terms

This article was originally published in a special issue, "Clinical Research in Pharmaceutical and Biomedical Sciences" Indian J Pharm Sci 2021:83(1)spl issue "211-214". 